\title{
Does the conceptual distinction between singular and plural sets depend on language?
}

\author{
Peggy Li ${ }^{1}$, Tamiko Ogura ${ }^{2}$, David Barner ${ }^{3}$, Shu-Ju Yang ${ }^{4}$, and Susan Carey ${ }^{1}$ \\ ${ }^{1}$ Harvard University \\ ${ }^{2}$ Kobe University \\ ${ }^{3}$ University of California, San Diego \\ ${ }^{4}$ University of Chicago
}

\begin{abstract}
Previous studies indicate that English-learning children acquire the distinction between singular and plural nouns between 22- and 24-months. Also, their use of the distinction is correlated with the capacity to distinguish non-linguistically between singular and plural sets in a manual search paradigm (Barner et al., 2007). Three experiments explored the causal relation between these two capacities. Relative to English, Japanese and Mandarin have impoverished singular-plural marking. Using the manual search task, Experiment 1 found that by around 22-months, Japanese children also distinguish between singular and plural sets. Experiments 2 and 3 extended this finding to Mandarin-learning toddlers. Twenty- to 24-month-old Mandarin-learners did not yet comprehend Mandarin singular-plural marking (i.e., yige vs. yixie, or -men), yet they did distinguish between singular and plural sets in manual search. These experiments suggest that knowledge of singular-plural morphology is not necessary for deploying the non-linguistic distinction between singular and plural sets.
\end{abstract}

\section{INTRODUCTION}

All languages allow speakers to express relations among sets, whether via nouns, numerals, quantifiers, or specialized morphology, such as singular-plural suffixes (e.g., a cat, some cats). However, languages vary in how they do this. While English and many other languages distinguish between singular and plural nouns, for example, others, like Japanese and Chinese, do not. Also, some languages lack integers and perhaps even quantifiers (Gordon, 2004; Pica et al., 2004). These cross-linguistic differences raise the question of whether linguistic representations of sets affect how speakers habitually think and reason about them. The present study investigated this question by testing whether children learning languages which lack obligatory singular-plural morpho-syntax are delayed relative to English-learning children in their capacity to distinguish between singular and plural sets in a non-linguistic task.

Although very young infants have a rich capacity to represent sets, previous studies have found a striking failure on the part of infants as old as 20-months to distinguish between sets of one and more than one, as such (i.e., to make a conceptual singular-plural distinction). When tracking small sets of individuals, young infants discriminate sets of 1, 2, and 3 (Carey, 2004; Feigenson \& Carey, 2003, 2005; Feigenson, Carey \& Spelke, 2002; 
Feigenson, Dehaene, \& Spelke, 2004; Wynn, 1998). When representing large sets, 6-montholds distinguish 4 vs. 8, 8 vs. 16, and 16 vs. 32 (Xu, 2003; Xu \& Spelke, 2000; Lipton \& Spelke, 2003; McCrink \& Wynn, 2004; Wood \& Spelke, 2005). However, infants as old as 20-months fail to distinguish between singular and plural sets, as such, under certain experimental conditions. In one investigation of object tracking in human infants, Feigenson and Carey (2005) demonstrated that 10- to 14-month-old infants can track up to 3 objects in parallel, but cannot resolve comparisons like 1 vs. 4 . When shown sets of crackers hidden one-at-a-time into two containers, 10- and 12-month-old infants crawled reliably to the larger set for comparisons of 1 vs. 3, 1 vs. 2, or 2 vs. 3. However, they chose at chance for 1 vs. 4 comparisons (Feigenson \& Carey, 2005). In another study, upon seeing 2 or 3 objects hidden in a box, 12-month-olds searched longer in the box after retrieving 1 object than if only 1 object was originally hidden. However, they did not search significantly longer after retrieving 1 if 4 objects had been originally hidden, indicating that they did not distinguish between 1 and 4 (Feigenson \& Carey, 2005). This pattern of results has been interpreted as evidence for a system of "parallel individuation" in infants, which allows them to represent up to three individuals at a time in working memory (see Feigenson, Hauser, \& Carey, 2002; Feigenson \& Carey, 2005; Leslie, Tremoulet, \& Scholl, 1998). By this account, each object in an array is represented with a distinct mental symbol, or index, but there is no symbol in the system that means "one", "four", or even "more than one". The specific failure at 1 vs. 4 supports this analysis, and also suggests that 14-month-olds fail to deploy a distinction between singular and plural sets in these tasks.

Barner, Thalwitz, Wood, Yang, \& Carey (2007) extended this 1 vs. 4 failure to infants aged 18- and even 20-months, and found that infants learning English first succeed as a group by 22 -months. On 1 vs. 4 trials, children watched as either 1 or 4 objects were hidden in the front of a box, and were encouraged to reach into the box and retrieve one. They were then allowed to search again during a ten-second measurement period. The 22- and 24-montholds searched longer after retrieving the one object when they had seen 4 hidden than when they had seen only one hidden. However, the 18- and 20-month-olds did not. Thus, unlike 12- to 20-month-olds, 22-month-old children learning English distinguished between sets of 1 and 4. This success was due to their representation of sets of four as "plural" or "more than one" rather than as four independently tracked objects. If they could track four objects as four individuals, they should know that when two objects are removed, two more still remain inside the box. Although children succeeded at the 1 vs. 4 comparison, these same children did not distinguish between sets of 2 and 4 . When 4 objects were hidden and infants had removed two, they failed to search longer than on trials in which 2 objects were originally hidden.

This treatment of sets as pluralities was correlated with children's use of singular-plural morphology in language production. Barner et al. (2007) asked parents whether their infants had begun producing plural morphology (using the MacArthur Communicative Development Inventory; Fenson et al., 1994). Almost all parents of the 20-month-olds said no, whereas those of 22- and 24-month-olds, for the most part, said yes. This is consistent with reports from diary studies, elicited production tasks, parental reports, and comprehension tasks, which converge on 22 to 24 months as the age at which English learning children first begin to mark the singular-plural distinction in language (Barner, Chow, \& Yang, 2009; Brown, 1973; Cazden, 1968; Clark \& Nikatina, in press; Fenson et al., 1994; Kouider, Halberda, Wood \& Carey, 2006; Mervis \& Johnson, 1991; Wood, Kouider, \& Carey, in press).

This correlation between acquiring singular-plural morphology and deploying a nonlinguistic distinction between singular and plural sets is open to two broad classes of interpretation; it could reflect an effect of language learning on thought, or, conversely, an 
effect of conceptual development on language development. If acquiring singular-plural morphology is the occasion for formulating the conceptual distinction between singular and plural sets (or if it makes an existing distinction more salient), then children learning languages which lack singular-plural morphology should be delayed in distinguishing singular and plural sets relative to children learning English. If, however, the mastery of the singular-plural distinction in English depends on antecedent conceptual development, then no differences should be found between children from different linguistic groups.

Experiment 1 begins to explore the causal relation between the acquisition of singular-plural morphology and the conceptual distinction between singular and plural sets by testing children learning Japanese. As a classifier language, Japanese does not have count syntax, and thus does not have obligatory singular-plural morpho-syntax. Although Japanese provides various means of expressing relations between sets (e.g., integers, classifiers, quantifiers), few of those present in 2-year-olds' vocabularies could support a singularplural distinction. For example, whereas English obligatorily distinguishes between "a ball" and "some balls", Japanese does not (though an infrequent, non-obligatory plural marker can be used for animates). Thus, a single sentence can be used to describe either a single object or a plural set of objects, as in (1):

(1) Kenji-wa booru-o motteiru.

Kenji-TOP ball-ACC have ${ }^{1}$

Kenji has a / some balls.

Also, Japanese children are delayed in acquiring the meaning of the word "one" relative to English-learning children. As a result, learning the word "one" could not help Japanese children distinguish singleton sets and plural sets at age 2 (Barner, Libenson, Cheung, \& Takasaki, in press; Sarnecka, Kamenskaya, Yamana, Ogura, \& Yudovina, 2007; Ogura \& Watamaki, 2008).

If singular-plural morphology drives the deployment of the conceptual singular-plural distinction in English-learning 22- to 24-month-olds, then Japanese children of the same age should fail at 1 vs. 4 comparisons (while succeeding at $1 \mathrm{vs.} 3$, which is within the limits of parallel individuation). However, if the conceptual distinction emerges independent of these linguistic structures, then we should expect no difference between Japanese and Englishlearning children. Set representations may emerge independent of language, or may depend on linguistic structures that are common to both Japanese and English.

\section{EXPERIMENT 1}

\section{Method}

Participants-English-learning children from Barner et al. (2007) reliably passed the manual search task at around 22 months of age. We, therefore, recruited 52 monolingual Japanese-learning children aged 19 months through 27 months ( $M=23.29,19 ; 3-27 ; 24)$ from Kobe, Japan. The children were recruited through leaflets left at several organizations (child-nurturing support centers, child pavilions, and pediatric hospitals) calling for parents to bring their children into the laboratory for developmental studies at Kobe University. The children were mainly from middle-class and their parents were at least high-school educated.

Once in the laboratory, the children were tested individually in a laboratory room by a native Japanese speaker. Matched to Barner et al.'s age groups, there were ten 20-month-olds (range: 19;3 to 20;29), twenty-one 22-month-olds (range: $21 ; 1$ to 22;15), and twenty-one 24-

\footnotetext{
${ }^{1}$ TOP=topic marker; $\mathrm{ACC}=$ accusative case marking
} 
month-olds (range: $23 ; 16$ to $27 ; 24$ ). Eleven additional children were excluded due to fussiness or parental interference.

Stimuli-Children were presented orange ping-pong balls that were placed inside a black foam-core box $(25 \mathrm{~cm}$ wide $\times 31.5 \mathrm{~cm}$ deep $\times 12.5 \mathrm{~cm}$ high $)$. The face of the box had a $14 \times$ $7.5 \mathrm{~cm}$ opening covered by red spandex material with a horizontal slit across its width. Unbeknownst to the child, the back of the box also had a large opening to allow the experimenter to surreptitiously remove ping-pong balls. Four metal washers were attached to the top of the box to stabilize balls as they were displayed.

To retrieve the balls at the end of each trial, the experimenter encouraged children to place them in a plastic chute (Ball-party, by TOMY).

Design and Procedure-Children sat on a chair next to their parent, in front of a small table. The experimenter sat across from the child with the box between them. The experiment included three stages: (1) familiarization, (2) a 1-ball vs. 4-ball block, and (3) a 1-ball vs. 3-ball block. Each test block consisted of four trials (two 1-ball trials and two trials with either 3 or 4 balls). The order of the test blocks and trials within blocks was counterbalanced, resulting in eight possible combinations. For example, in the 1 vs. 3 condition children saw either the larger number of balls presented first (e.g., 3-1-1-3) or the smaller number of balls presented first (e.g., 1-3-3-1). Half of the children received the 1 vs. 3 block first, and half received the 1 vs. 4 block first.

Familiarization-A large, multi-colored ball was used for familiarization. The experimenter showed the child the box and hid the ball inside it, saying (in Japanese), "Look, look what I have. See? What's in the box?" The child was encouraged to reach into the box and retrieve the ball. Familiarization was complete once the child successfully retrieved the ball and placed it into the chute once.

1 vs. 4 block-In the 1-ball vs. 4-ball condition (see Figure 1), we compared trials where the experimenter initially placed one ball in the box with those where the experimenter initially placed four balls in the box. On 1-ball trials, the experimenter held up one ball and said "Look!", placed the ball on top of the box and repeated, "Look!" The ball was then placed in the box via the opening in the front. Next, the experimenter moved the box forward within the reach of the child and asked, "What's in the box?" Once the child retrieved the ball, the box was pulled back and the child encouraged to place the ball down the chute. Once completed, the experimenter pulled the chute back and slid the box forward again. A 10-second measurement period began when the box came to rest, during which the experimenter averted gaze to the floor and did not engage with the child. A timer was placed such that when the experimenter lowered her gaze she could read off the time. If the child was no longer searching at the end of the 10-second period, the trial ended. These one-ball test trials were called "1-in-1-out, expected empty" trials, because one ball was hidden and one ball was retrieved.

Four-ball trials were nearly identical to 1-ball trials. The experiment held up four balls in one hand and said "Look!" The experimenter then proceeded to place the four balls, one at a time, on top of the box. Once the balls are on top of the box, the experimenter again directed the child's attention to the balls by saying "Look!" Then in one grab, the experimenter moved all the balls into the box and pushed the box within reach of the child, just like the 1ball trials. Children, having seen the four balls hidden in the box, were then allowed to retrieve one (the other three were surreptitiously removed by the experimenter via the opening in the back of the back). After the ball was placed in the chute, a 10-second 
measurement period began. The 4-ball test trials were called "4-in-1-out, expected full" trials, because four balls were hidden and one was removed.

1 vs. 3 block-The 1 vs. 3 block was identical to the 1 vs. 4 block except that three balls were hidden instead of four on the multiple ball trials. On half of the trials, children saw three balls go in the box, were allowed to retrieve one (the other two were surreptitiously removed), and they were then allowed to search for the remaining balls for 10 seconds. These were called " 3 -in-1-out, expected full" trials. On the other half of trials, children saw one ball go in the box, were allowed to retrieve it, and then were allowed to search the box. Like in the 1 vs. 4 test phase, these were called "1-in-1-out, expected empty" trials.

Children were considered to be searching if their hand passed through the slit beyond the second set of knuckles and they were actively attending to the box. Two separate observers, naïve to the purpose of the experiment, coded the search time by playing the digitized video of the test session frame-by-frame. The two observers were in 95\% agreement (average correlation between searching times across trials).

\section{Results}

Search times for expected empty and expected full trial pairs were compared. Trial pairs in which one of the search times was 2 standard deviations greater than the average for trials of that type were removed from the analysis. Five pairs (10 trials of 144) were removed. We assessed whether there were age related differences in Japanese children's capacity to distinguish 1 vs. 3 relative to their capacity to distinguish 1 vs. 4 . In other words, the comparisons of interest were between the expected empty trials (1-in-1-out) and the respective expected full trials (3-in-1-out or 4-in-1-out). Since 3 is within children's objecttracking capacity, we expected Japanese-learning children, like Barner et al.'s Englishlearning children, to succeed at the 1 vs. 3 comparison at all ages tested. However, Englishlearning children only begin to succeed at 1 vs. 4 at around 22-months-old. Critically, if Japanese-learning children represent sets of 4 as "more than one", despite the lack of singular-plural morphology in their language, then they should start to succeed at the 1 vs. 4 comparison at around 22-months-old as English-learning children. However, if learning singular-plural morphology is relevant in the deployment of singular-plural representation in solving 1 vs. 4, Japanese-learning children should succeed at a later age than Englishlearning children.

Results are shown in Figure 2. A $2 \times 2 \times 2 \times 3$ ANOVA examined the effects of Block type (1 vs. 3 or 1 vs. 4), Trial type (3-in-1-out or 4-in-1-out, expected full, or 1-in-1-out, expected empty), Block order (1 vs. 3 or 1 vs. 4 block first), and Age (20-months vs. 22-months vs. 24-months) on search time. The analysis found a main effect of Trial Type $(\mathrm{F}(1,46)=$ $35.31, \mathrm{p}<.001, \eta_{\mathrm{p}}{ }^{2}=.43$ ), indicating that infants searched longer on expected full trials $(2.79 \mathrm{~s})$ than on expected empty trials (1.41s). However, there were no main effects or interactions due to Age or Block type. Planned comparisons confirmed that the Japanese children searched significantly more on 3-in-1-out trials than on 1-in-1-out trials at 20months $\left(\mathrm{t}(9)=2.45, \mathrm{p}<.05, \mathrm{~d}=.90, \mathrm{CI}_{95}=.10 \mathrm{~s}, 2.5 \mathrm{~s}\right), 22$-months $(\mathrm{t}(20)=2.91, \mathrm{p}<.01, \mathrm{~d}$ $\left.=.74, \mathrm{CI}_{95}=.40 \mathrm{~s}, 2.43 \mathrm{~s}\right)$, and 24-months $\left(\mathrm{t}(20)=4.13, \mathrm{p}<.005, \mathrm{~d}=.98, \mathrm{CI}_{95}=.78 \mathrm{~s}\right.$, 2.37s). Importantly, the results showed that these children could succeed at 1 vs. 3 comparisons, just as many previous studies from other laboratories have shown that young infants could succeed at 1 vs. 3 by tracking individuals in parallel (e.g., Feigenson \& Carey, 2003,2005;Barner et al., 2007). Without demonstrating the expected success on 1 vs. 3, any failure on the part of the children to distinguish 1 vs. 4 might have been attributable to differences due to laboratories. 
Having demonstrated success on 1 vs. 3 , we turned to the 1 vs. 4 trials. Planned comparisons showed that the Japanese learners searched significantly more on 4-in-1-out, expected full trials than on 1-in-1-out, expected empty trials at 22-months $(\mathrm{t}(20)=3.02, \mathrm{p}<.01, \mathrm{~d}=.78$, $\left.\mathrm{CI}_{95}=.39 \mathrm{~s}, 2.14 \mathrm{~s}\right)$, and 24-months $\left(\mathrm{t}(20)=3.48, \mathrm{p}<.005, \mathrm{~d}=.78, \mathrm{CI}_{95}=.56 \mathrm{~s}, 2.24 \mathrm{~s}\right)$. Also, like English-learning children, the Japanese participants did not succeed at 20-months $(\mathrm{t}(9)=$ $\left.1.92, \mathrm{p}>.05, \mathrm{~d}=.81, \mathrm{CI}_{95}=-.23 \mathrm{~s}, 2.83 \mathrm{~s}\right)$. This failure may reflect a lack of power $(\mathrm{N}=10$ participants), since the mean search time difference between the expected full and expected empty trials were comparable in magnitude across 1 vs. 4 and 1 vs. 3 for the 20-month-olds. Similarly, the difference between the expected full and empty trials for the 1 vs. 4 comparisons was as great in magnitude for 20-month-olds as for 22-month-olds. There were no interactions involving age in this study.

\section{Discussion}

By at least 22-months, Japanese children distinguish robustly between sets of 1 and 3 and 1 and 4. Since English children in Barner et al.'s (2007) study first succeeded at 1 vs. 4 at 22months, the crucial question was whether Japanese children would succeed later than this, due to a lack of singular-plural morphology in their language. The data presented here indicate no such delay.

These data provide preliminary evidence against the hypothesis that singular-plural morphology plays a necessary role in the construction of this distinction, or in deploying the distinction in non-linguistic contexts. For further evidence, Experiments 2 and 3 sought to replicate this finding in another classifier language, Mandarin Chinese. This replication allowed us to test two additional questions. First, Experiment 1 leaves open the possibility that children learning a classifier language may draw on other forms of singular-plural marking. Classifier languages are not devoid of singular-plural cues, and among such languages, availability and frequency of such markings varies. Thus, Experiment 2 tested Mandarin-learning children's comprehension of Mandarin singular-plural cues. Second, Japanese children's success on the 1 vs. 4 comparison, though consistent with representing a set of 4 objects as a plural, might also be due to an increased attentional capacity. Crucially, as mentioned in the introduction, Barner et al. ruled this out by testing a 2 vs. 4 comparison. We do the same with this new group of children. Thus, we tested Mandarin children not only with a 1 vs. 4 comparison, but also with 2 vs. 4 .

Mandarin has very little inflectional morphology, no number agreement on verbs, and no true singular-plural morphology on nouns (Li \& Thompson, 1989). The closest "plural" or collective marker is -men ( $\mathrm{Li}, 1999)$, which is restricted to nouns denoting animate beings (ayi-men, "aunts", *beizi-men, "cups"), but is obligatory on pronouns. Plural first, second, and third person pronouns are composed of the singular pronoun forms with the -men suffix added (i.e., respectively, wo $\rightarrow$ wo-men, ni $\rightarrow$ ni-men, ta $\rightarrow$ ta-men). However, because Mandarin allows noun and pronoun omissions when its referents are evident from contextual cues or previous mention (e.g., Tardif, Shatz, \& Naigles, 1997), there is sparse linguistic evidence of plural marking in Mandarin input. ${ }^{2}$ Mandarin also marks a singular-plural distinction in its quantifier system, between "yige" (one) and "yixie" (some). Although 22month-olds are unlikely to comprehend such words, they remain a possible source of the conceptual distinction in early acquisition.

\footnotetext{
${ }^{2}$ Examination of maternal speech in the CHILDES corpora (all 10 transcripts of 20-month-old Mandarin learners in the Zhou1 corpus vs. the first 10 transcripts of 20-month-old English learners in the New England corpus) confirmed the paucity of plural marking in Mandarin. In the Mandarin corpus, 27\% (2864 out of 10599) of the words were pronouns and nouns. The -men marker occurred $0.4 \%$ of the time (39 words out of 10599), and only on the pronouns and not on any nouns. In contrast, the English corpus had more pronouns and nouns combined (38\% of the words), and the plural $-s$ marker occurred $1.4 \%$ of the time (228 words out of 16008). This frequency is 3.5 times that of Mandarin, independent of the fact that English pronouns also has distinct singular and plural forms and its verbs are often marked for singular and plural.
} 
Experiment 2 tested 18- to 30-months-olds' comprehension of both the -men morpheme and also the contrast between yige and yixie. Having established the age at which children begin learning these words, we then tested younger Mandarin-learning children with 1 vs. 4 and 2 vs. 4 comparisons using the manual search task in Experiment 3.

\section{EXPERIMENT 2}

\section{Method}

Participants-Twenty-three native Mandarin-learning children were recruited from Taipei, Taiwan through personal contacts, daycares, and school organizations. Leaflets about the study were left at the organizations encouraging parents to sign up their children. The children tested were mainly middle class families, and most parents had at least completed a high school education.

The children were tested individually by a native Mandarin-speaking experimenter in a quiet room either at their home, school, or organization from which they were recruited. The children were divided into two age groups: twelve younger children $(\mathrm{M}=22.8$ month-old; range 18;25-25;21), and eleven older children ( $M=28.2$ month-old; range 26;12-30;1). The younger group matched the age at which most English-learning children begin to understand and produce plural morphology (Fenson et al. 1994; Kouider et al., 2006; Barner et al., 2007), and also matched the age of the participants in Experiment 3. Seven additional children were excluded from analysis because they failed practice trials even after feedback.

Stimuli-For each test trial, children were presented with two photographs as choices and asked to match a sentence to one of them. There were four pairs of photographs for quantifiers and four pairs for pronouns, for a total of eight test trials. For the quantifiers, the pair consisted of a photograph with one object (a cup, an apple, a present, or a doll) and a photograph with multiple objects of the same kind. The pronoun pairs always consisted of a photograph of a character doing something (eating, sleeping, watching TV, or dancing) and a photograph of multiple characters doing the same thing.

In addition to the test pairs, two practice pairs of photographs were created. One pair depicted a crying baby vs. a smiling baby. The other pair depicted a boy vs. a girl.

Design and Procedure-The instructions in Mandarin for the practice and test trials are shown in the Appendix. For each test trial, the experimenter first held up two photographs to show the child. Next, she described the photographs without indicating which particular one she was describing (e.g., "I have one cup and some cups. Look. One side has one cup. The other side has some cups."). The experimenter then placed the photographs in front of the child and asked them to point to a requested photograph ("Which side has one cup?"). The word that was mentioned first and then queried (e.g. yige "one" or yixie "some") was counterbalanced across participants. The placement of the photographs (left vs. right side) was also counterbalanced.

Two practice trials, structured like test trials, familiarized the children to the procedure using photographs and utterances that were irrelevant to the singular-plural distinction. To ensure the child understood the task, the experimenter provided feedback during the practice trials for the incorrect responses by labeling the photographs (e.g. "This side baby is crying. This side baby is smiling."), and immediately testing the child on the same question ("Which side is the baby crying?"). Any child who could not answer questions following feedback was excluded from the study. No corrections or retests were given for the test trials. 


\section{Results}

For each trial, correct responses were coded as "1" and incorrect responses were coded as "0". A correct response means choosing the photograph showing one object or individual for yige (one) and $t a$ (s/he), and the photograph showing multiple objects or individuals photographs for yixie (some) and ta-men (they). An incorrect response means choosing the other photograph. On $12.5 \%$ of trials, children pointed to both photographs despite being told to select one of two sides. These trials are inconclusive of children's knowledge and resulted in a code of .5. Children could have chosen both photographs because they were unable to distinguish singular and plural morphology. Alternatively, they could have chosen both in the case of plural morphology because both photographs together depicted a plural set (e.g., of presents). For singular morphology, they could have chosen both because each contained either one or subsets of one (e.g., one present among many). The percentage correct for each participant was then determined by averaging the coded scores across trials.

Figure 3a shows the average percentage correct on the practice trials, prior to feedback. Younger children were correct $79 \%$ of the time, compared to $96 \%$ for the older group. Both groups' performance differed from chance (t-tests, $p$ 's $<.05$, two-tailed, d's $>1.5$ ), and there was no significant difference between them $(\mathrm{t}(21)=1.28, \mathrm{p}>.20, \mathrm{~d}=.55)$. Thus, children understood that the task required selecting the photograph that matched the experimenter's request.

Children had less success with test questions (compare Figure $3 b$ with Figure $3 a$ ). The percentage correct was entered into a 2 Trial Type (quantifiers vs. pronouns) $\times 2$ Question Type (singular vs. plural) $\times 2$ Age (young vs. old), ANOVA with Age as a between-subjects factor. There were no main effects or interactions (all $\mathrm{p}>.1$ ). The older group performed no better than the younger group ( $61 \%$ vs. 54\%), and there were no interactions between Age and other factors (closest was Trial Type $\times$ Age; $F(1,21)=2.82, \mathrm{p}=.10 ; \eta_{\mathrm{p}}{ }^{2}=.12$ ). Performance on the singular (yige and ta) questions was similar to the plural (yixie and tamen) questions (58\% vs. 57\%). Performance on the quantifier trials (54\%) was comparable to the pronoun trials $(60 \%)$. Planned comparisons revealed one significant difference: older children distinguished singular and plural pronouns $68 \%$ of the time, which was better than chance $\left(\mathrm{t}(10)=2.75, \mathrm{p}<.05, \mathrm{~d}=1.74, \mathrm{CI}_{95}=3.5 \%, 32.9 \%\right)$, whereas younger children did not $(53 \%)$.

\section{Discussion}

A test of Mandarin-learning children's comprehension of number morphology found that (1) neither 22- nor 28-month-olds understood the lexical contrast between yixie (some) and yige (one), and (2) 28-month-olds children, but not 22-month-olds distinguished between tamen (they) and $t a(h e)$.

By comparison, studies of English-learning children place the earliest understanding of singular-plural morphology at between 20- and 24-four-months (Brown, 1973; Cazden, 1968, Fenson et al. 1994; Barner et al., 2007; Clark \& Nikatina, in press; Mervis \& Johnson, 1991; Kouider et al. 2006; Wood et al., in press). In a very similar experiment to this one, Kouider et al. (2006) presented English-learning children with a sentence (e.g., "There are some blickets" or "There is a blicket") and measured looking time to two screens, depicting either one novel object or several novel objects of another kind. At 24-months but not 20months, children looked reliably longer at the appropriate screen. Thus, English-learning children acquire singular-plural morphology earlier than Mandarin-learning children.

Prior studies on number word acquisition also suggest that Japanese- and Mandarin-learning children are several months delayed in learning the meaning of the word "one" relative to English-learning children (Barner et al., under review.; Sarnecka et al. 2007; Li, Le Corre, 
Shi, Gia, \& Carey, 2003). When asked to give the experimenter one (yige) object, Japanese and Mandarin 2 and 3-year-olds often give a random number of objects instead of one. In fact, $\mathrm{Li}$ et al. found that that Mandarin-learning children did not understand "one" until 36 months of age. It is therefore unsurprising that 22- and 28-month-olds did not distinguish yixie (some) from yige (one).

\section{EXPERIMENT 3}

Having established that Mandarin-learning children are unlikely to comprehend singularplural cues by 24-months, we can ask whether language learning affects the deployment of a non-linguistic singular-plural distinction. If it does, then Mandarin-learning children under 24-months should fail to distinguish between 1 vs. 4 on the manual search task. If it does not, then Mandarin speaking children, like Japanese children, should succeed on 1 vs. 4.

We tested Mandarin-learning children with the 1 vs. 4 comparison as we did with Japanese children in Experiment 1. Also, children were tested with a 2 vs. 4 comparison to determine whether success on 1 vs. 4 is due to an increase in children's set size limit or whether they are treating set sizes of four as plural. Success on 1 vs. 4 comparison is compatible with singular-plural knowledge, but also consistent with the ability to track sets of exactly four objects in parallel. If success at a 1 vs. 4 comparison is due to increased ability to track four objects via parallel individuation, children should also succeed at a 2 vs. 4 comparison. They should know that when 4 objects were hidden and 2 were retrieved that exactly 2 remained. However, if success is driven by a singular-plural distinction, then they should not. Barner et al. (2007) found that the same English-learning 22-months-olds who succeeded at 1 vs. 4 failed at 2 vs. 4 . These children did not search longer on 4-in-2-out (expected full) trials than 2-in-2-out (expected empty) trials, suggesting that they encoded the set of four balls as "some balls" or "more than one." Thus, if Mandarin learners also represent 4 objects as a plural set, they should succeed at 1 vs. 4 and fail at 2 vs. 4 like English learners.

\section{Method}

Participants-Twenty-three native Mandarin-learning children ( $\mathrm{M}=22.15$ month-old, $17 ; 0-25 ; 21)$ were recruited in the same manner and from the same population as Experiment 2 . The children were mainly middle class families, and most parents had at least completed a high school education. The children were divided into three groups according to age: seven 19-month-olds $(\mathrm{M}=18.9$; range 17;0-20;0), seven 22-month-olds $(\mathrm{M}=22.0$, range $=21 ; 4-22 ; 24)$, nine 24-month-olds $(\mathrm{M}=24.2$, range $23 ; 0-25 ; 21)$. Children were tested individually, sometimes accompanied by a caretaker. Twelve additional children were excluded because of their refusal to participate $(n=8)$, or for having search times at least two standard deviations above the group average $(n=4)$.

Stimuli, Design, and Procedure-With two exceptions, the stimuli, design, and procedure were identical to Experiment 1. First, the children were tested in Mandarin by an experimenter who also tested children in Barner et al. (2007). Second, the 1 vs. 3 block was replaced with the 2 vs. 4 block described below.

2 vs. 4 block: The 2 vs. 4 block was nearly identical to the 1 vs. 4 block. For these trials, the experimenter hid either 2 balls or 4 balls in the box. For both the 2-ball trials and the 4-ball trials children were allowed to retrieve two balls before the 10 -second measurement period began. Thus, on half of the trials children saw two balls go into the box and were allowed to retrieve two balls one at a time, to put down the chute. After the second ball was placed down the chute, the experimenter once again pushed the box in front of the child and averted her gaze for the 10-second measurement period. These were called "2-in-2-out, expected empty" trials. On the other half of the trials (i.e., the 4-ball trials), children saw four balls go 
in the box and were allowed to retrieve two (the other two were surreptitiously removed by the experimenter via the opening in the back of the box)., They were then allowed to search for the remaining balls for the 10-second measurement period. These trials were called " 4 in-2-out, expected full" trials.

\section{Results \& Discussion}

Search time during the measurement periods was measured and calculated as in Experiment 1. Two separate observers coded the digitized video frame-by-frame. Their times were then averaged. The coders were in agreement on $94 \%$ of the trials.

Figure 4 plots the average search times for each age group. The search times were entered into a 2 Block Type ( 1 vs. 4 or 2 vs. 4$) \times 2$ Trial Type (expected empty vs. box expected full) $\times 2$ Block Order ( 1 vs. 4 or 2 vs. 4 block first), and 3 Age (19-months, 22-months, or 24-months) ANOVA, with Block Order and Age as between-subjects factors. There was a main effect of Trial Type: children searched longer on trials when the box was supposedly "full" (4.9s) than when the box was empty $\left(3.18 \mathrm{~s} ; \mathrm{F}(1,17)=26.17, \mathrm{p}<.001 ; \eta_{\mathrm{p}}{ }^{2}=.61\right)$. An interaction of Block Type by Trial Type $\left(\mathrm{F}(1,17)=8.28, \mathrm{p}=.01 ; \eta_{\mathrm{p}}^{2}=.33\right)$ indicate that search times for the expected full versus the expected empty varied according to whether the comparison block was 1 vs. 4 (1-in-1-out vs. 4-in-1-out) or 2 vs. 4 (2-in-2-out vs. 4-in-2out). Children searched longer on 4-ball trials than on 1-ball trials $(5.4 \mathrm{~s}$ vs. $2.5 \mathrm{~s} ; \mathrm{t}(22)=$ $\left.5.82, \mathrm{p}<.001 ; \mathrm{d}=1.14 ; \mathrm{CI}_{95}=1.8 \mathrm{~s}, 3.9 \mathrm{~s}\right)$ but showed no difference between 4-ball trials and 2-ball trials ( $3.9 \mathrm{~s}$ vs. $\left.3.4 \mathrm{~s} ; \mathrm{t}(22)=1.33, \mathrm{p}>.20 ; \mathrm{d}=0.23 ; \mathrm{CI}_{95}=-.27,1.2\right)$. For the 1 vs. 4 comparison, 19 out of 23 children searched longer on 4-ball trials than 1 -ball trial $(\mathrm{p}<.002$, binomial test). In comparison, 11 out of 23 children searched longer for the 4-ball trials than the 2 ball-trials in the 2 vs. 4 comparison $(\mathrm{p}=1)$. The success at 1 vs. 4 but not 2 vs. 4 was true for every age group (see Figure 3). This pattern indicates that the 1 vs. 4 success was not driven by a general increase in the capacity of the parallel individuation system (relative to younger infants), but instead by an emerging capacity to treat sets of "more than one" as equivalent under certain circumstances, and as distinct from sets of exactly one.

Importantly, Mandarin-learning children succeeded at 1 vs. 4 at around the same age, if not earlier, than English-learning children in Barner et al.'s study. The earlier success by Mandarin-learning children could be driven by differences in the English and Mandarin children's willingness to focus on the task at hand. Anecdotally, looking at the videotapes of children doing the search task, Taiwanese and Japanese toddlers were quieter and calmer than the American toddlers. At any rate, learning Mandarin does not delay children's capacity to represent the singular-plural distinction non-linguistically.

\section{GENERAL DISCUSSION}

The results from this study indicate that if any causal relationship exists between language and the emergence of a conceptual singular-plural distinction, then it is the conceptual distinction that must support the acquisition of singular-plural morphology, and not the opposite. In Experiment 1, Japanese children were not delayed relative to English-learning children for 1 vs. 4 comparisons, suggesting that success at the task is not driven by the acquisition of singular-plural morphology in language.

Converging evidence is provided by the Mandarin-learning children. Two experiments establish that Mandarin-learning children deploy the non-linguistic singular-plural distinction in a manual search task (Experiment 3), while lacking explicit morphological or lexical expression of the contrast in their language (Experiment 2). Although Mandarin provides certain non-obligatory devices for expressing the distinction between singular and plural sets, children failed to distinguish the words for one and some (yige and yixie) even by 
28-months, and did not show signs of understanding the plural marker (-men) at the ages tested in Experiment 2 (see also Li et al., 2003; and Sarnecka et al., 2007, for evidence from Japanese). These forms may emerge later in Mandarin due to the lower frequency in speech to children. However, their absence in language appears to have little effect on children's capacity to distinguish singular and plural sets, relative to children learning English.

Mandarin-learning children succeed at the non-linguistic manual search task at the same age as, if not earlier than, English-learning children. Children learning Mandarin Chinese, which also lacks singular-plural morpho-syntax, distinguish 1 vs. 4 by at early as 20-months. The Mandarin-learning children also show the same pattern of failure as English-learning children on 2 vs. 4 , further demonstrating that success on the 1 vs. 4 in children was not due to an increase in the working memory capacity to track four individuals in parallel.

One question left open by the present study is why distinguishing singular and plural sets emerges when it does in development, and why it is so closely related to the development of singular-plural morpho-syntax in children learning English. In fact, the non-linguistic capacity to distinguish between singular and plural sets may emerge well before 22-months in children learning English, but may be triggered only under very specific conditions, not created in the current study. Barner, Kibbe, Wood, \& Carey (under review) reported that 15month-old infants successfully distinguished 1 vs. 2,1 vs. 3 , and 1 vs. 4, but not 2 vs. 3 or 2 vs. 4 when objects were presented as united sets that always moved together. Thus, infants succeeded at all singular-plural comparisons but failed at comparisons involving two plural sets, even when these sets both contained three objects or less (i.e., were within the limits of infants' object tracking capacities). As in the task described here, infants watched as balls were hidden in a box, and their searching was measured after having retrieved one or two objects. However, unlike previous studies, the objects (pingpong balls) were fixed with glue to a small presentation board, to ensure that they moved as a united set. Apparently, Gestalt cues like common fate are taken by infants as cues to set membership (Wynn, Bloom, \& Chiang, 2002; see also Barner, Wood, Hauser, \& Carey, 2008, for similar evidence from non-human primates). Recent studies by Feigenson and colleagues suggest that other perceptual cues, such as color, shape, and the spatial segregation of objects may also lead infants to treat objects as members of sets (Feigenson, under review). Given this evidence, infants may distinguish between single individuals and plural sets at a young age, but only in contexts that provide clear perceptual cues to set membership. Thus, we believe that the developmental change observed here concerns the likelihood of deploying this distinction under the conditions of the present experiment - when objects move independently, and when sethood is not defined by strictly spatio-temporal cues.

Why then, does this capacity emerge when it does? One possibility is that treating arbitrary groupings of objects as set members is related to language after all, and that the capacity emerges due to the acquisition of linguistic structures that are common to Japanese, Mandarin, and English. For example, all three languages have lexical forms that represent sets, such as quantifiers. Although our data from Mandarin learners suggest that being able to categorically distinguish one ball from some balls is not facilitated by or dependent upon the acquisition of the specific quantifiers "one" and "some", it remains possible that the acquisition of other quantifiers could still engage children in thinking about set relations. Presently, almost nothing is known about quantifier comprehension in very young language learners (see Barner, Chow, \& Yang, 2009; Barner et al., in press).

Another possibility is that learning names for kinds of things - like cats, balls, and trucks engages the notion of set inclusion, and thus the distinction between sets and individuals. Kind representations specify sets not in terms of number per se, but rather in terms of category membership, to which we know infants are sensitive well before they begin producing plural nouns (Quinn \& Eimas, 1997). A large body of evidence indicates that 
when children acquire English, Japanese, and other languages, their inventory of nouns and thus of kind terms - surges between 18- and 24-months. This surge in word learning is highly correlated with spontaneous categorization (Gopnik \& Meltzoff, 1987, 1992), and is tightly yoked to morphological and syntactic development (e.g., Bates \& Goodman, 1997; Caselli, Casadio, \& Bates, 1999; Fenson et al., 1994; Goldfield \& Resnick, 1990; Ogura, 1991, 2000; Nelson, 1973; Snedeker, Geren, \& Shafto, 2007). Thus, rapid vocabulary growth could drive both the acquisition of singular plural and the success on 1 vs. 4 search without there being a direct causal link between the two. Future studies should investigate this by testing the relation between manual search behavior and vocabulary size, to determine whether language may indeed play a subtle role in rendering singular-plural representations more salient prior to its expression via singular-plural morphology.

\section{Acknowledgments}

Special thanks to Kozue Fukumoto and Masayo Kasahara for collecting the Japanese data, Katherine Chow and Raluca Ulici for coding the data, and Barbara Sarnecka for discussions. Special thanks to Shu-Ju Yang's family for help in recruiting children in Taiwan, and Leah Bogsted and Raegan Tennant for coding the data. This research was supported by the Grant-in-Aid for Scientific Research (B) from the Japan Society for the Promotion of Science (JSPS) to T.O. (\#17330142), a Harvard University Graduate Society Dissertation Completion Fellowship to D.B., a Harvard University Mind, Brain and Behavior Graduate Award to D.B., and by a grant from the National Sciences and Engineering Research Council of Canada to D.B., and was funded by a U.S. National Institute of Health grant (RO1-HD038338) to S.C..

\section{REFERENCES}

Barner D, Chow K, Yang SJ. Finding one's meaning: A test of the relation between quantifiers and integers in language development. Cognitive Psychology 2009;58:195-219. [PubMed: 18799157]

Barner D, Libenson A, Cheung P, Takasaki M. Cross-linguistic relations between quantifiers and numerals in language acquisition: Evidence from Japanese. Journal of Experimental Child Psychology. (in press).

Barner D, Kibbe M, Wood J, Carey S. Evidence for a non-linguistic singular-plural distinction in 15month-old children. (under review).

Barner D, Thalwitz D, Wood J, Yang S, Carey S. On the relation between the acquisition of singularplural morpho-syntax and the conceptual distinction between one and more than one. Developmental Science 2007;10(3):365-373. [PubMed: 17444976]

Barner D, Wood J, Hauser M, Carey S. Evidence for a non-linguistic distinction between singular and plural sets in rhesus monkeys. Cognition 2008;107(2):603-622. [PubMed: 18164282]

Bates E, Goodman JC. On the inseparability of grammar and the lexicon: Evidence from acquisition, aphasia, and real-time processing. Language and Cognitive Processes 1997;12:507-584.

Brown, R. A first language: The early stages. London, England: Allen \& Unwin; 1973.

Carey S. Bootstrapping and the origins of concepts. Daedalus 2004:59-68.

Caselli MC, Casadio P, Bates E. A comparison of the transition from first words to grammar in English and Italian. Journal of Child Language 1999;26:69-111. [PubMed: 10217890]

Cazden C. The acquisition of noun verb inflections. Child Development 1968;39(2):433-448. [PubMed: 5649958]

Clark EV, Nikatina TN. One vs. more than one: Antecedents to plurality in early language acquisition. To appear in Linguistics. in press).

Feigenson L, Carey S. Tracking individuals via object files: Evidence from infants' manual search. Developmental Science 2003;6:568-584.

Feigenson L, Carey S. On the limits of infants' quantification of small object arrays. Cognition 2005;97:295-313. [PubMed: 16260263]

Feigenson L, Carey S, Hauser M. The representations underlying infants' choice of more: Object files vs. analog magnitudes. Psychological Science 2002;13:150-156. [PubMed: 11933999]

Feigenson L, Dehaene S, Spelke ES. Core systems of number. Trends in Cognitive. Science 2004;7:307-314. 
Feigenson L, Carey S, Spelke ES. Infants' discrimination of number vs. continuous extent. Cognitive Psychology 2002;44:33-66. [PubMed: 11814309]

Fenson L. Variability in early communicative development. Monographs of the Society for Research in Child Development 1994;59(5):173-185.

Fenson L, Dale PS, Reznick JS, Bates E, Thal D, Pethick S. Variability in early communicative development. Monographs of the Society for Research in Child Development 1994;Vol. 59:242. No. 5, Serial \#.

Goldfield BA, Reznick JS. Early lexical acquisition : rate, content, and the vocabulary spurt. Journal of Child Language 1990;17:171-183. [PubMed: 2312640]

Gopnik A, Meltzoff AN. The development of categorization in the second year and its relation to other cognitive and linguistic developments. Child Development 1987;58:1523-1531.

Gopnik A, Meltzoff AN. Categorization and naming: Basic-level sorting in 18-month-olds and its relation to language. Child Development 1992;63:1091-1103.

Gordon P. Numerical cognition without words: Evidence from Amazonia. Science 2004;306:496-499. [PubMed: 15319490]

Kouider S, Halberda J, Wood JN, Carey S. The acquisition of English number marking: the singularPlural distinction. Language Learning and Development 2006;2(1):1-25.

Leslie A, Xu F, Tremoulet P, Scholl B. Indexing and the object concept: "what" and "where" in infancy. Trends in Cognitive Sciences 1998;2:10-18.

Li, CN.; Thompson, SA. Mandarin Chinese: A Functional Reference Grammar. Santa Barbara: University of California Press; 1989.

Lipton JS, Spelke ES. Origins of number sense: Large number discrimination in human infants. Psychological Science 2003;15 396-340.

McCrink K, Wynn K. Large-number addition and subtraction in infants. Psychological Science 2004;15:776-781. [PubMed: 15482450]

Mervis C, Johnson KE. Acquisition of the plural morpheme: A case study. Developmental Psychology 1991;27(2):222-235.

Nelson, K. Structure and strategy in learning to talk. Chicago: University of Chicago Press; 1973.

Ogura T. A longitudinal study of the relationship between early language development and play development. Journal of Child Language 1991;18:273-294. [PubMed: 1874828]

Ogura, T. Beijing, China: Paper presented a the XVIth Biennial meeting of International Society for the Study of Behavioral Development; 2000 Jul. The relationship between lexical development and grammatical development.

Ogura T, Watamaki T. Lexical Development Norms for Japanese children through the Japanese MacArthur Communicative Development Inventories. Bulletin of Kyoto International Social Welfare Exchange Center 2008;24:3-42.

Pica P, Lemer C, Izard V, Dehaene S. Exact and approximate arithmetic in an Amazonian Indigene Group. Science 2004;306(5695):499-503. [PubMed: 15486303]

Quinn PC, Eimas PD. A reexamination of the perceptual-to- conceptual. shift in mental representations. Review of General Psychology 1997;1:271-287.

Sarnecka BW, Kamenskaya VG, Yamana Y, Ogura T, Yudovina JB. From grammatical number to exact numbers: Early meanings of "one," "two," and "three" in English, Russian, and Japanese. Cognitive Psychology 2007;55:136-168. [PubMed: 17070794]

Snedeker J, Geren J, Shafto C. Starting over: International adoption as a natural experiment in language development. Psychological Science 2007;18:79-87. [PubMed: 17362382]

Wood JN, Kouider S, Carey S. The emergence of the singular/plural distinction. (in press).

Wood JN, Spelke ES. Infants' enumeration of actions: Numerical discrimination and its signature limits. Developmental Science 2005;8:173-181. [PubMed: 15720375]

Wynn K. Psychological foundations of number: Numerical competence in human infants. Trends in Cognitive Sciences 1998;2:296-303.

Wynn K, Bloom P, Chiang W. Enumeration of collective entities by 5-month-old infants. Cognition 2002;83(3):55-62. 
Xu F. Numerosity discrimination in infants: Evidence for two systems of representation. Cognition 2003;89:15-25.

Xu F, Spelke ES. Large number discrimination in 6-month-old infants. Cognition 2000;74:1-11. [PubMed: 10594308]

\section{APPENDIX}

FORMAT for PRACTICE and TEST TRIALS

Wo you ___ he __.
I have ___ and ___
'I have ___ and ___.'

Kan. Yi bian you ___. Lingwai yi bian you ___. Na bian you ___ ?

Look. One side have ___. Other one side have ___. Which side have ___ ?

'Look. One side has ___. The other side has ___. Which side has ___?

PRACTICE TRIAL EXAMPLE

Sister vs. Brother Trial (Querying Sister Example)

Yi bian you jiejie. Lingwai yi bian you gege. $\quad \mathrm{Na}$ bian you jiejie?

One side have big-sister. Other one side have big-brother. Which side have big-sister?

'One side has a big-sister. The other side has a big-brother. Which side has a big-sister?

Crying vs. Smiling Trial (Querying Crying Example)

Yi bian you wawa zai ku. Lingwai yi bian you wawa zai xiao. Na bian you wawa zai ku?

One side have baby PROG cry. Other one side have baby PROG smile. Which side have baby PROG cry?

'One side the baby is crying. The other side the baby is smiling. Which side is the baby crying?'

\section{TEST TRIAL EXAMPLES}

Quantifier Trials (Singular Trial Example)

Yi bian you yige beizi. Lingwai yi bian you yixie beizi. Na bian you yige beizi?

One side have one cup. Other one side have some cup. Which side have one cup?

'One side has one cup. The other side has some cups. Which side has one cup?"

Pronoun Trials (Singular Trial Example)

Yi bian you ta zai shuijiao. Lingwai yi bian you tamen zai shuijiao. Na bian you ta zai shuijiao? 
One side have he PROG sleep. Other one side have they PROG sleep. Which side have he PROG sleep?

'One side has he is sleeping. The other side has they are sleeping. Which side he is sleeping?'

Nouns for the Quantifier Trials: beizi (cup), pingguo (apple), liwu (present), (wawa) doll

Verbs for the Pronoun Trials: chifan (eat meal), shuijiao (sleep), kan dianshi (watch TV), tiaowu (dance)

$*$ PROG $=$ progressive marker 
1 object trial: 1 object hidden and retrieved by infant (expected empty at measurement)

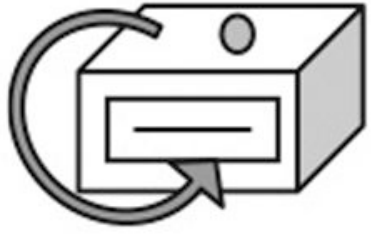

1) Experimenter places one ball on box then hides it inside

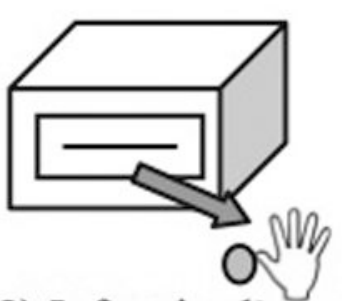

2) Infant is allowed to retrieve one ball

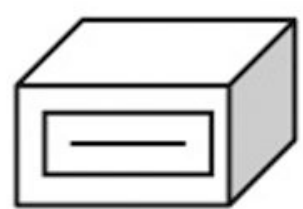

3) Infant's

subsequent searching is measured (1-in-1out, expected empty)

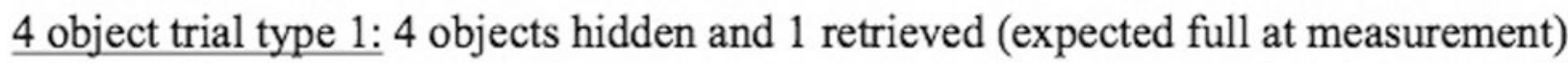

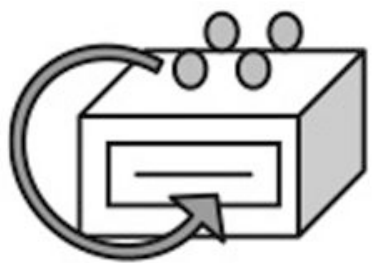

1) Experimenter places 4 balls on box then hides them inside

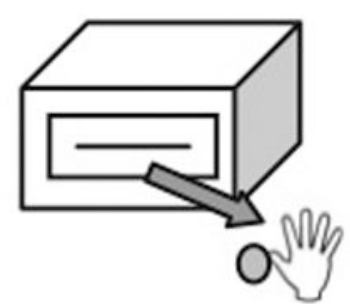

2) Infant is allowed to retrieve one ball

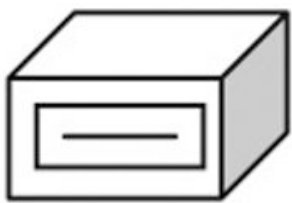

3) Infant's subsequent searching is measured (4-in-1out, expected full)

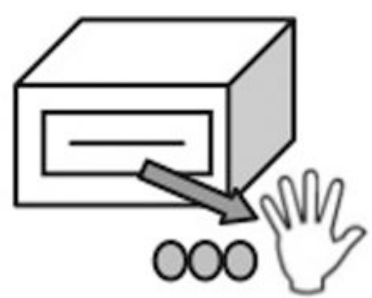

4) Experimenter retrieves remaining balls

Figure 1.

One-object and four-object trials. 


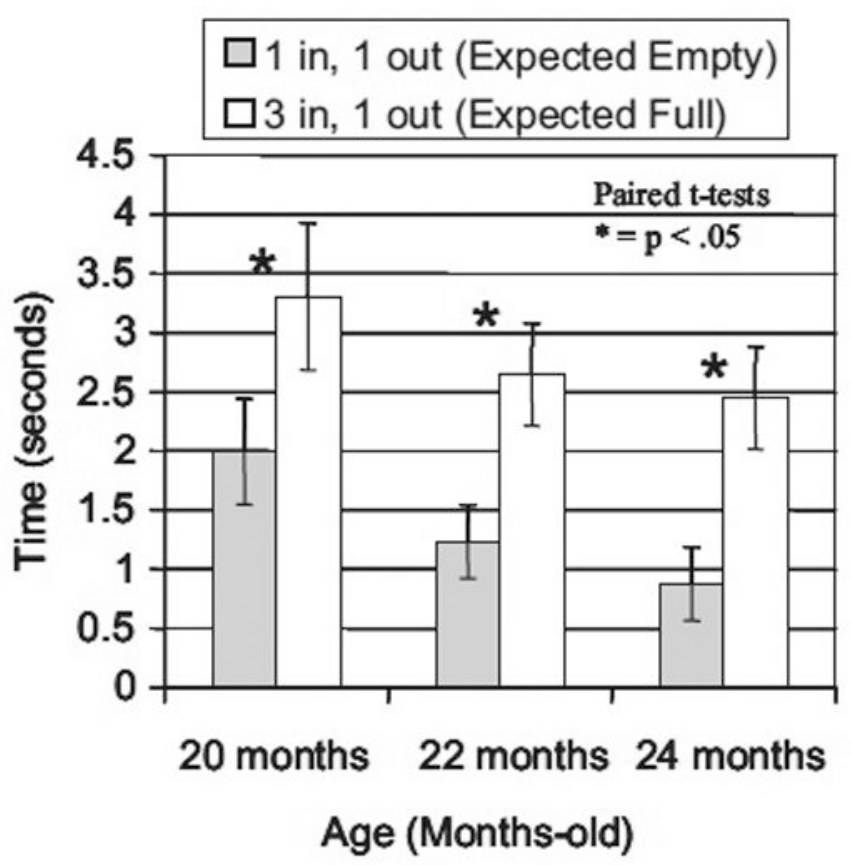

(a)

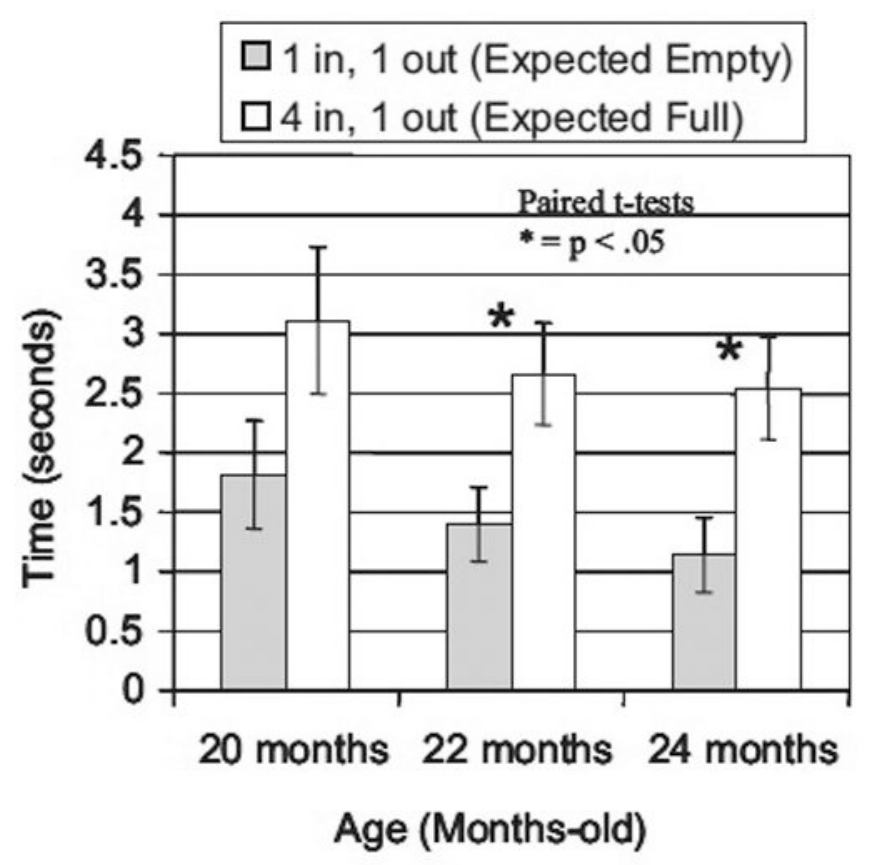

(b)

Figure 2.

Japanese-speaking children's average searching times for (a) 1 versus 3 comparison trials and (b) 1 versus 4 trials during the measurement period (after retrieving one ball). Error bars represent standard error. 


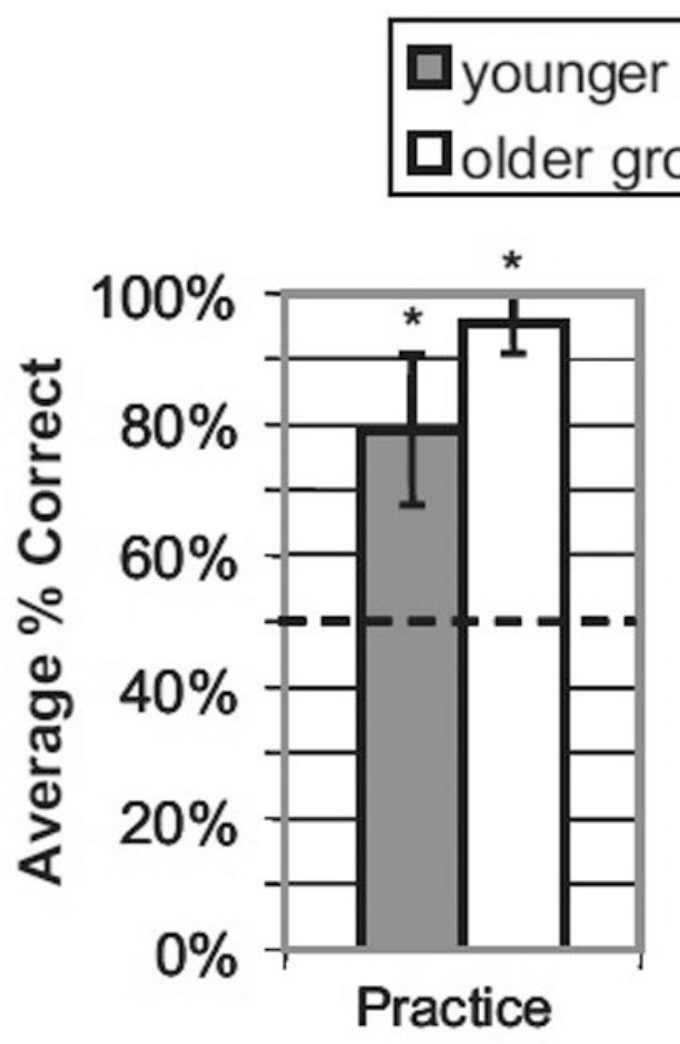

(a)

(b)

Figure 3.

Results from (a) practice trials and (b) test trials of the language comprehension task (Experiment 2). Error bars represent standard error. 


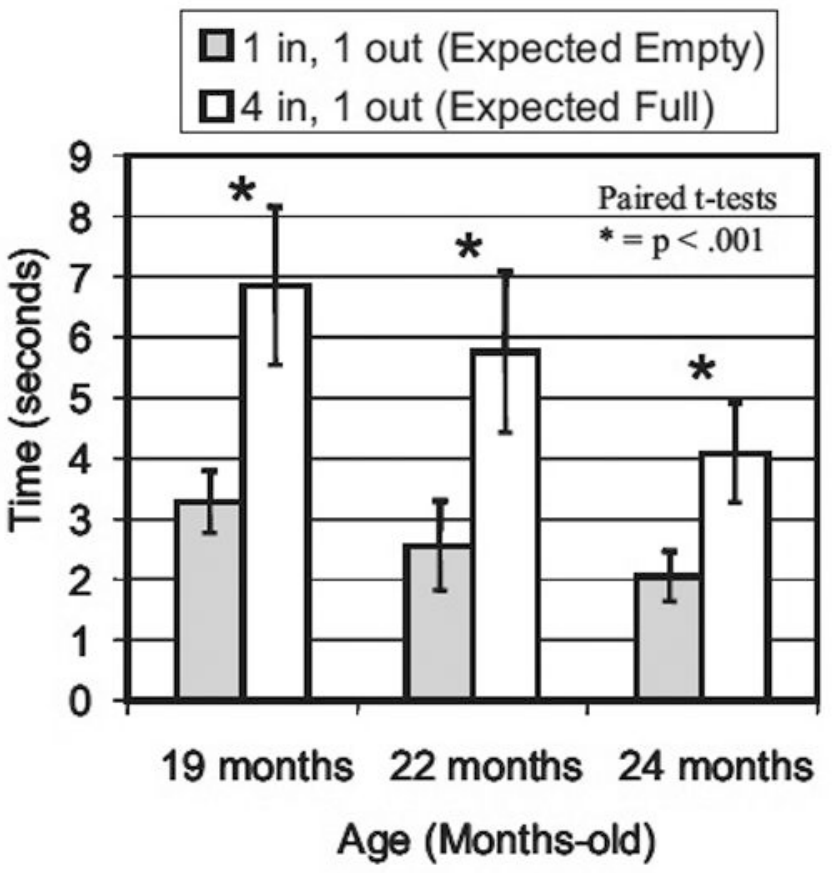

(a)

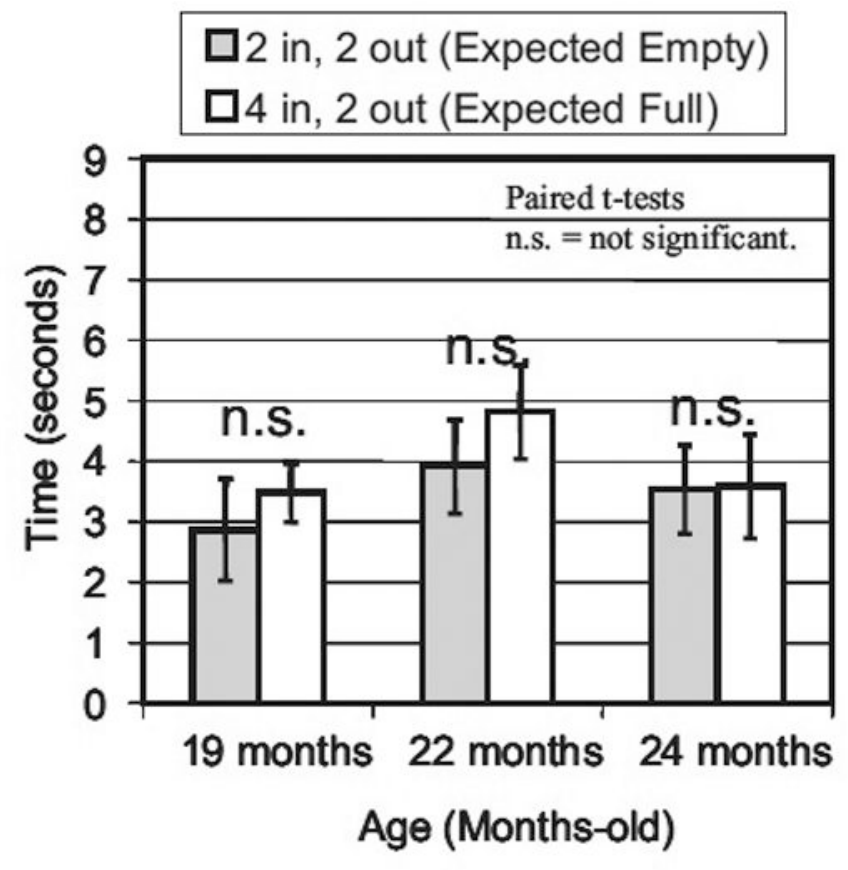

(b)

Figure 4.

Mandarin-speaking children's average searching times for (a) 1 versus 4 comparison trials and (b) 2 versus 4 trials during the measurement period (after retrieving one ball). Error bars represent standard error. 